\title{
POSSIBILITIES OF DEGASSING OF AISi7Mg0.3 ALLOY WITH ARGON AND NITROGEN
}

\author{
${ }^{1}$ Tomáš OBZINA, ${ }^{1}$ Martina GAWRONOVÁ, ${ }^{2}$ Isabel NGUYENOVÁ, ${ }^{2}$ Miroslav DOSTÁL \\ ${ }^{1}$ VSB - Technical University of Ostrava, Czech Republic, EU, tomas.obzina@vsb.cz \\ ${ }^{2}$ Brembo Czech, s.r.o., Ostrava, Czech Republic, EU
}

https://doi.org/10.37904/metal.2021.4252

\begin{abstract}
Hydrogen in aluminum alloys is generally considered to be a predominantly adverse gas. It affects cleanliness, porosity and other mechanical and foundry properties. Therefore is an effort to eliminate this gas as much as possible. This study will focus on comparing the efficiency of commonly available refinery gases, namely nitrogen and argon. For the purpose of the research, one specific shape of the impeller or refining head will be chosen. The comparison of degassing efficiency will be evaluated using known tests that are commonly available in every non-ferrous metal foundry with a focus on aluminum alloys. The evaluation will be demonstrated by the Density Index, a comparison of the microstructures and a test to assess the amount of inclusions in the alloy called Drosstes.
\end{abstract}

Keywords: Degassing, aluminum, density index, microstructures, Drosstest

\section{INTRODUCTION}

It is a well-known fact that the only gas that is able to dissolve in aluminum alloys is hydrogen, and this has been confirmed by several authors [1,2]. Hydrogen in aluminum and its alloys forms the so-called porosity, which is unfavourable in almost all cases. It results in a decrease in mechanical properties $[3,4]$. In order to reduce the porosity or hydrogen content, it is necessary to use one of the refining methods. For example, one study [5] applies ultrasonic vibration with a combination of argon blowing. However, according to another sources [6-8] the most used degassing methods are rotor devices, which reduce the hydrogen content to the desired values within a few minutes. The principle of the machine consists in blowing an inert gas into the molten alloy bath. The incurred gas bubbles are broken into very small bubbles by the high speed of the rotor, which float to the surface of the melt. Due to the flotation and the slow ascent speed to the surface, hydrogen diffuses into the bubbles with zero hydrogen partial pressure $[9,10]$.

Commonly used refining media are argon and nitrogen [11,12]. Some studies have reported that aluminum in combination with nitrogen can form nitrides. However, in foundry practice, this process is unlikely to occur due to thermodynamic conditions [13]. Regarding the degassing efficiency, the authors [11] concluded that argon is endowed withbetter degassing effects.

This study will focus on comparing the degassing efficiency of argon and nitrogen as degassing media. To compare the individual results, the following tests will be used: determination of density index, microstructure evaluation and Drosstest to assess the amount of inclusions.

\section{MATERIALS AND METHOD}

For the research, AISi7Mg0.3 alloy was chosen, which was melted in an electric crucible furnace with a volume of $250 \mathrm{~kg}$, at $710^{\circ} \mathrm{C}$. The graphite rotor (Figure 1) was placed $150 \mathrm{~mm}$ from the bottom of the crucible. During degassing/refining constant speed of the impeller was chosen, 500 RPM. Two gases were selected as the refining medium, specifically nitrogen and argon. The flow rate of both refining media was set at $10.5 \mathrm{l} / \mathrm{min}$. 


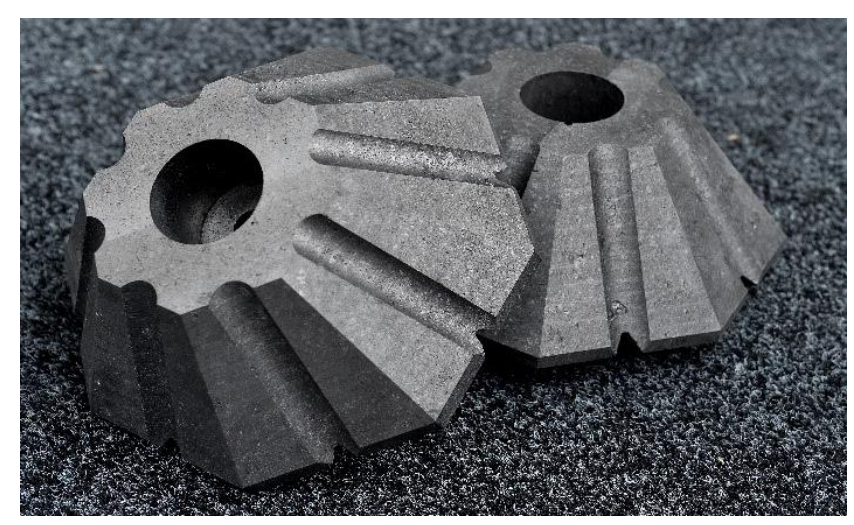

Figure 1 The shape of the impeller used during the experiment

In the first step (see Table 1), the alloy was melted and appropriate samples (sample 1) were taken for all the tests mentioned below. In the second step, the alloy was refined with argon (sample 2) for 6 minutes. In the next series, a new alloy was melted; again the necessary samples were taken (sample 3). Subsequently, refining with argon (sample 4) was carried out, in this case with half the time, for 3 minutes. The same procedure was carried out in the case of nitrogen refining (samples $5-8$ ). Samples were taken from each operation for the following tests: Density Index (DI), microstructure evaluation and Drosstest.

\section{RESULTS AND DISCUSSION}

\subsection{Density Index (DI)}

For each operation 3 samples were taken under the same preparation conditions ( $30 \mathrm{mbar}$ ), from which the average result was calculated, see Table 1. A better overview is then obtained from the graphical representation, see Figure 2.

Table 1 The average values of density index

\begin{tabular}{|c|c|c|c|c|}
\hline \multirow{2}{*}{ Samples } & \multirow{2}{*}{$\begin{array}{c}\text { Density } \\
\text { index (\%) }\end{array}$} & \multicolumn{2}{|c|}{ Density $\left(\mathrm{kg} \cdot \mathrm{m}^{-3}\right)$} & \multirow{2}{*}{$\begin{array}{l}\text { Hydrogen content } \\
\left(\mathrm{m}^{3} \mathrm{H}_{2} / \mathrm{kg} \mathrm{Al}\right)\end{array}$} \\
\hline & & $\rho_{\text {underpressure }}$ & $\rho_{\text {atmosphere }}$ & \\
\hline Sample 1 (After melting a new batch of alloy) & 3.48 & 2.5448 & 2.6367 & 0.0136 \\
\hline Sample 2 (Refining $\mathbf{A r}_{2} \mathbf{6}$ min.) & 0.53 & 2.6317 & 2.6459 & 0.0020 \\
\hline Sample 3 (After melting a new batch of alloy) & 4.37 & 2.5104 & 2.6253 & 0.0174 \\
\hline Sample 4 (Refining $\operatorname{Ar}_{2} 3$ min.) & 0.65 & 2.6252 & 2.6425 & 0.0024 \\
\hline Sample 5 (After melting a new batch of alloy) & 3.79 & 2.5134 & 2.6126 & 0.0151 \\
\hline Sample 6 (Refining $\mathbf{N}_{\mathbf{2}} \mathbf{6} \mathbf{m i n}$.) & 1.61 & 2.6001 & 2.6427 & 0.0062 \\
\hline Sample 7 (After melting a new batch of alloy) & 3.99 & 2.5094 & 2.6139 & 0.0159 \\
\hline Sample 8(Refining $\mathrm{N}_{2} 3 \mathrm{~min}$.) & 2.20 & 2.5824 & 2.6405 & 0.0085 \\
\hline
\end{tabular}

The density index of the molten alloy (sample 1), intended for argon refining, was $D I=3.48 \%$. The refining process (sample 2) reduced this value to $D I=0.58 \%$. After melting the newly inserted charge (sample 3 ), the value was $D I=4.37 \%$. A 3 minutes refining process (sample 4) resulted in $D I=0.65 \%$. A partial conclusion can be drawn: the efficiency of the 6 and 3 minutes refining processes is almost the same when using argon as a refining medium. 
The $D /$ value of the molten alloy (sample 5), intended for refining with nitrogen, was $D I=3.79 \%$. By subsequent 6 min refining (sample 6) the value was reduced to $D I=1.61 \%$. The newly loaded and molten charge (sample 7) with a value of $D I=3.99 \%$ was subsequently refined (sample 8 ) for 3 minutes when the measured value resulted in $D I=2.20 \%$. From the previous results, a partial conclusion can be drawn when using nitrogen as a refining medium. From the values, it can be seen that the 3 minutes refining is not as efficient. Therefore, it is preferable to use twice the refining time, 6 minutes.

Then if we compare the results obtained from the refining of each gas, argon vs. nitrogen, the words of the authors [14] can be confirmed: when using argon as a refining medium, the degassing of the molten alloy is many times more efficient. This statement is supported by the results of the density index measurements, where a six-minutes degassing with argon is many times more efficient.

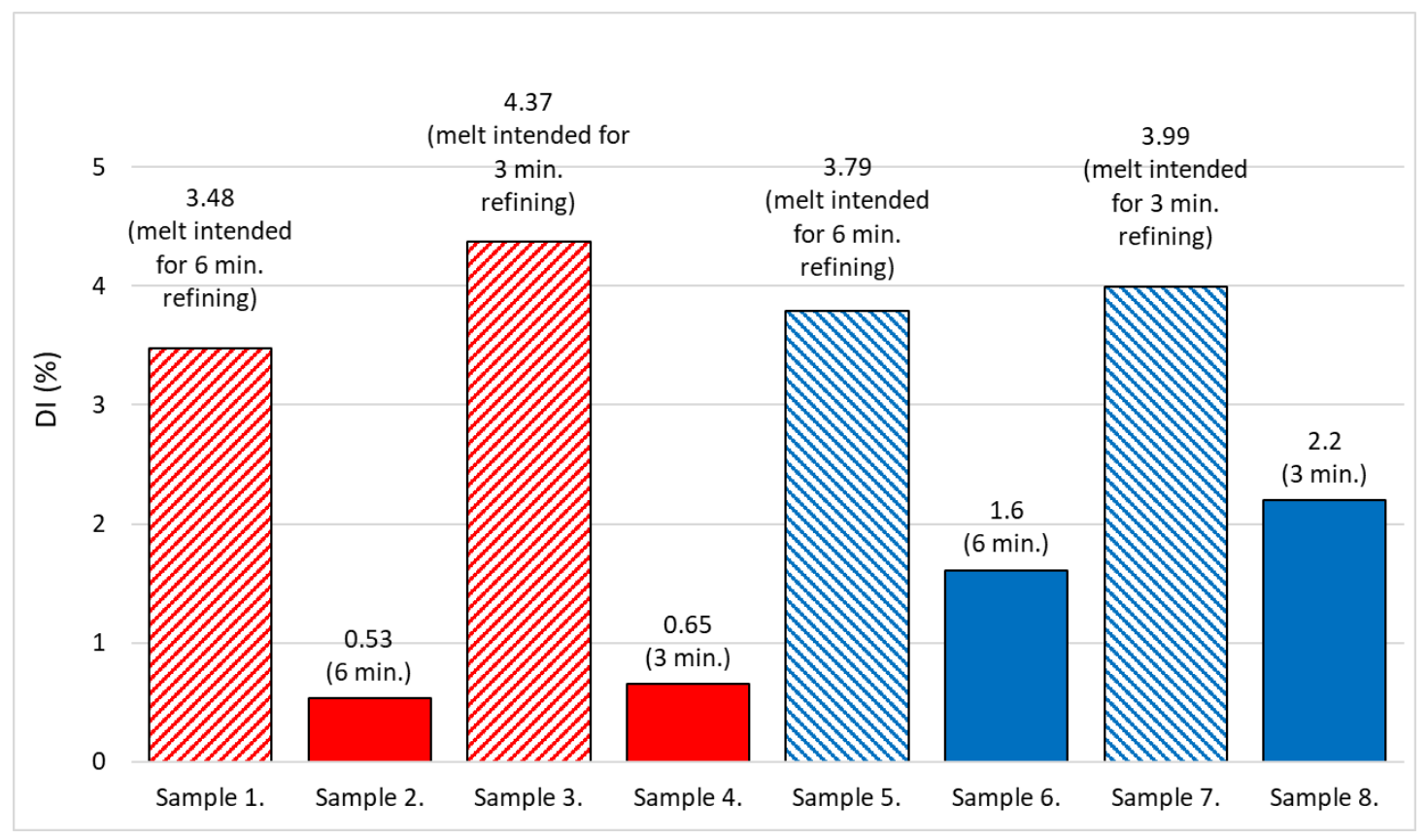

Figure 2 Density index comparison

\subsection{Evaluation of microstructure}

The microstructures were evaluated on cast samples under standard conditions where the metal was cast into metal moulds at normal room temperature $\left(25^{\circ} \mathrm{C}\right)$. The casting temperature was set as in the case of refining, respectively $710^{\circ} \mathrm{C}$. All the following images of the microstructures (Figures 2 to 5 ) are taken with a scale of $700 \mu \mathrm{m}$. In the first operation (sample 1)was taken a sample of the unrefined melt intendedfor 6 minutes argon degassing, see Figure 2 (left). The metal structure shows the presence of various inclusions/oxidation films and cavities mainly caused by hydrogen. The microstructure of the alloy prior to 6 minutes nitrogen refining is photographed in Figure 2, right. As in the previous case, oxide films and minor cavities can be observed. The subsequent 6 minutes refining/degassing resulted in a compact structure, see Figure 3, where the structure on the left is completely clear, on the right a small gas cavity can be seen. Figure 4 then shows the microstructure of the unrefined melt intended for the 3 minutes degassing. In both cases the presence of gas cavities can be seen. However, no oxide films are visible on the right. The melt was subjected to a 3 minutes refining/ degassing process to obtain better structural properties. If we compare the resulting microstructuresin term of the refining media efficiency, it is not clear which refining gas is more efficient. It can be argued that in this case of microstructure evaluation both media achieve comparable results for both 6 and 3 minutes refining/degassing. 

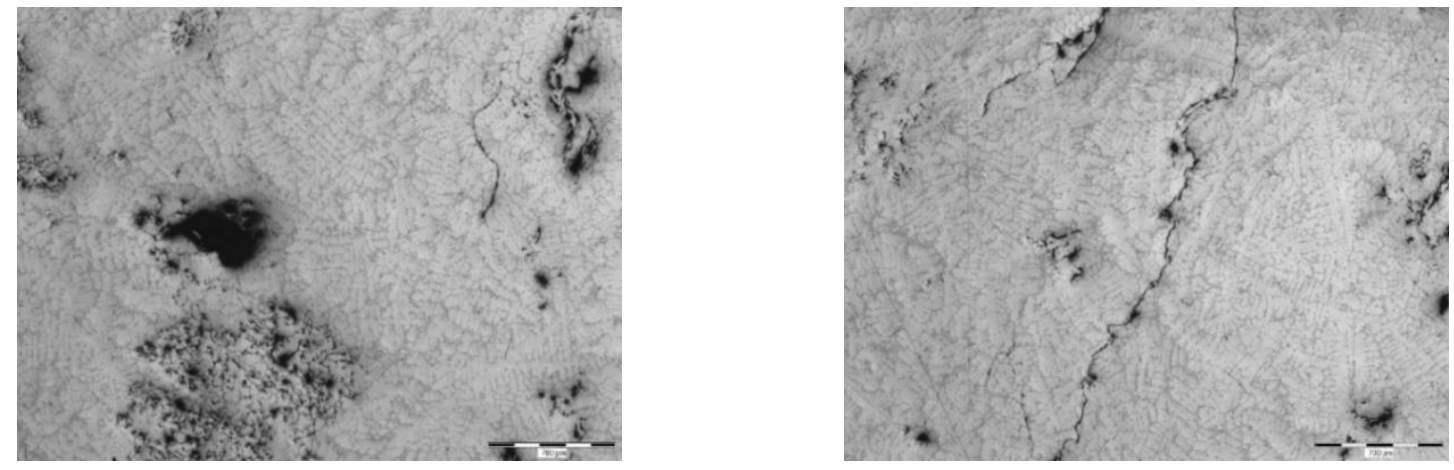

Figure 2 Microstructure after melting, intended for 6 minutes argon refining/ degassing (left) Microstructure after melting, intended for 6 minutes nitrogen refining/degassing (right)
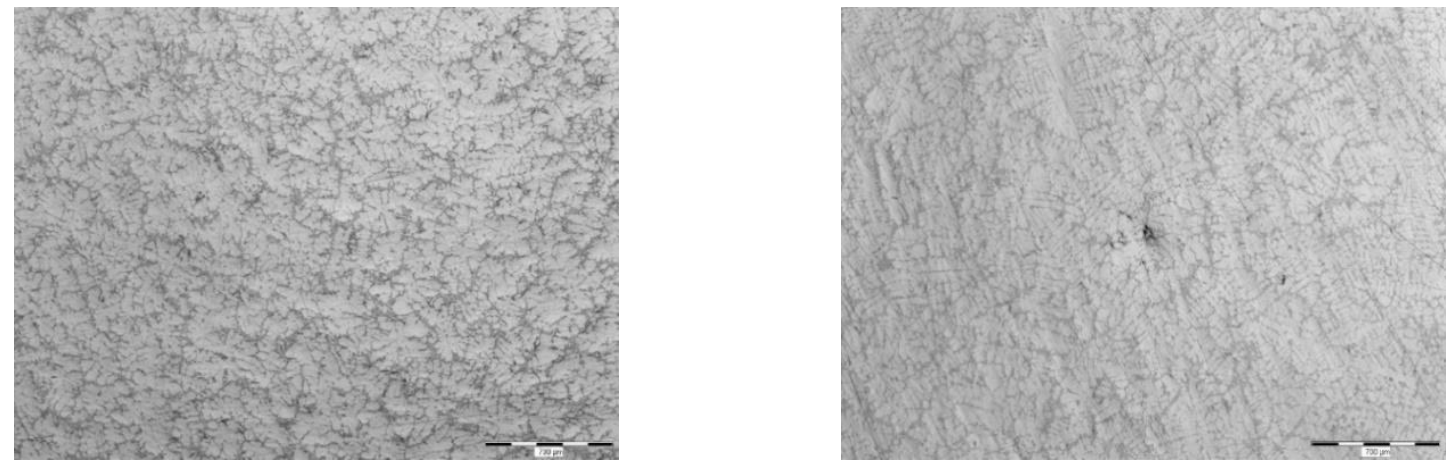

Figure 3 Refining by argon, 6 minutes (left) Refining by nitrogen, 6 minutes (right)
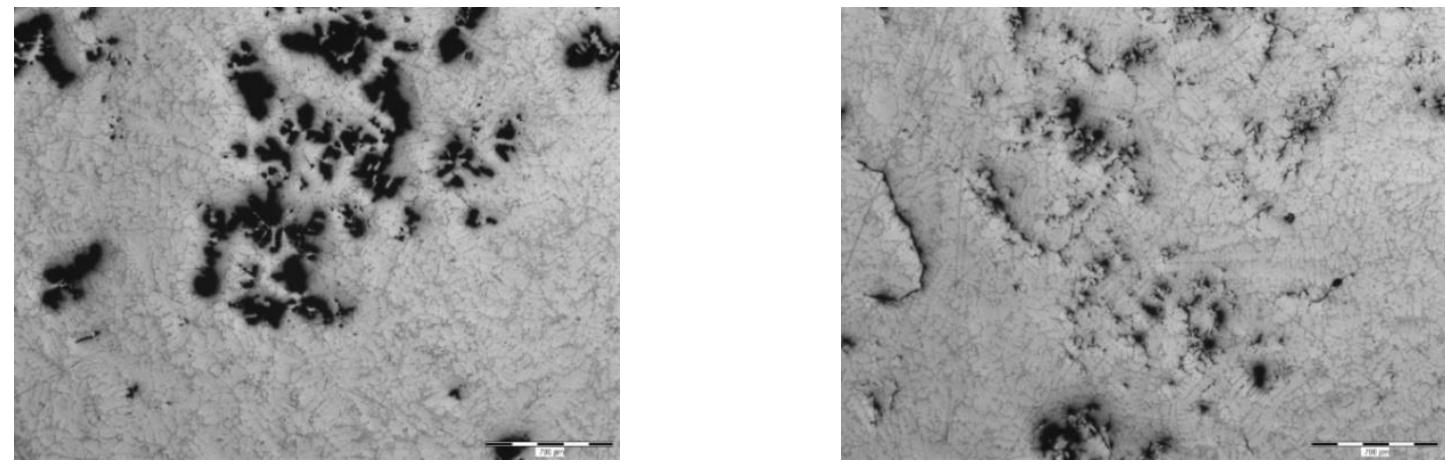

Figure 4 Microstructure after melting, intended for 3 minutes argon refining/ degassing (left) Microstructure after melting, intended for 3 minutes nitrogen refining/degassing (right)
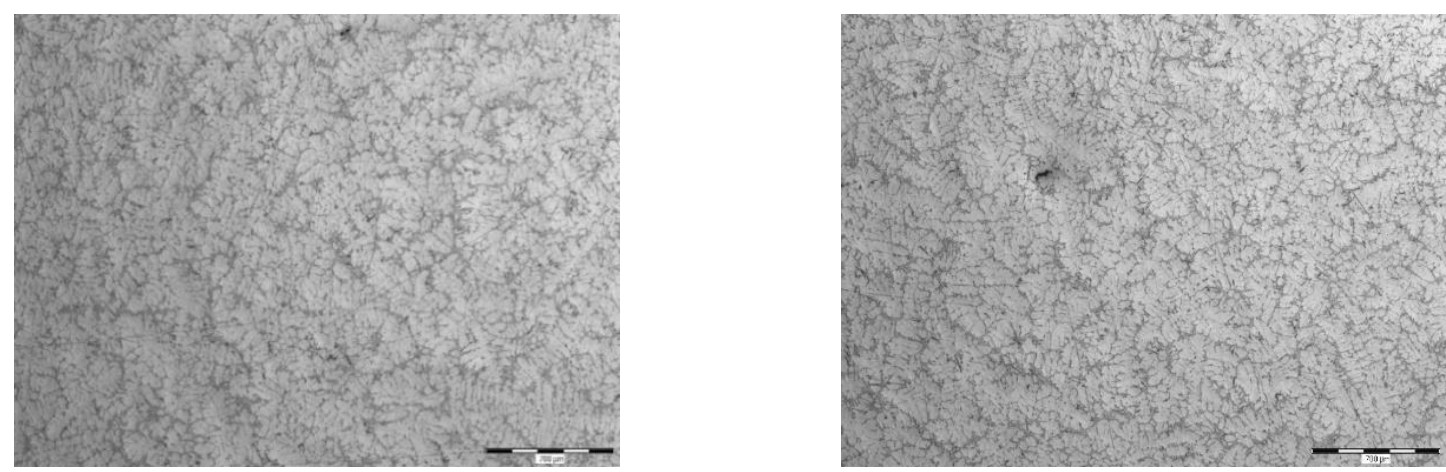

Figure 5 Refining by argon, 3 minutes (left) Refining by nitrogen, 3 minutes (right) 


\subsection{Drosstest}

The evaluated photographs for the Drosstes test are shown in Figure 6. The samples were prepared under a vacuum of 8 mbar. The photographs show the number that corresponds to the appropriate step in Table 1. As expected, samples 1, 3, 5 and 7 correspond to the state before refining and a high incidence of inclusions on the surface can be seen. Samples 2 and 4 were refined with argon for 6 and 3 minutes, respectively. Samples 6 and 8 were refined with nitrogen, also for 6 and 3 minutes. On closer examination, the results given in the previous tests can be clearly confirmed. Argon achieves better refining capabilities than nitrogen. The surfaces are less porous and more compact. Also as expected the refining time is evident on the samples. Those refined for 6 minutes contain fewer inclusions than those refined for half that time.
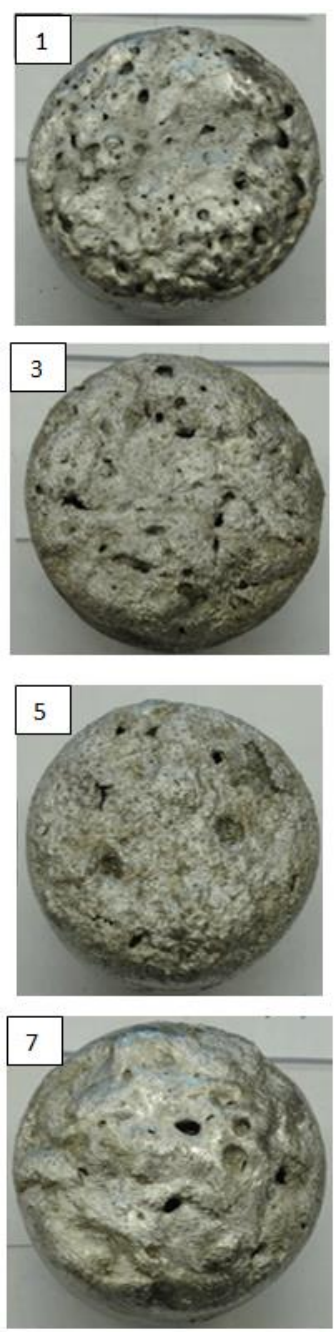
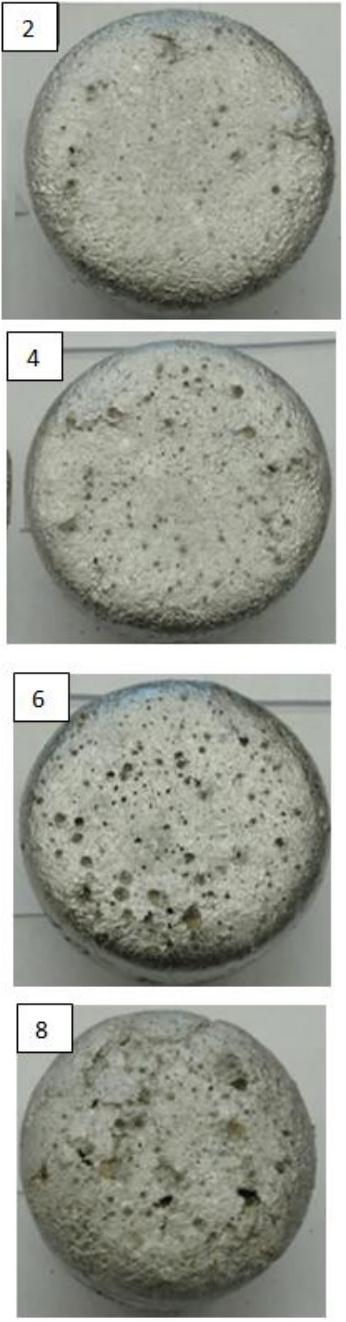

Figure 6Amount of excluded inclusions

\section{CONCLUSION}

Thework was focused on the comparison of the refining efficiency of argon and nitrogen in AlSi7Mg0.3 alloy. The comparison was carried out using several tests: the Dichtelndex evaluation, the microstructure evaluation and the Drosstest evaluation. Density Index - the results obtained indicate a high refining efficiency of argon, where the DI values for both 6 minutes and 3 minutes refining were several times lower. Differences between refining times were also noticed. In the case of argon, the results differed only in tenths of percent. However, for nitrogen refining the differences were several times higher. 
Microstructure evaluation - In all cases of refined samples, no significant structural defects were observed in the photographs and it cannot be clearly determined which refining gas has the higher refining ability.

Drosstest - Inclusion formation is evident on the samples prior to refining when the surface is rough and wrinkled. Subsequent refining then reduced the oxide films on the individual surfaces. A combination of argontogether with a longer degassing time is then suitable for refining purposes. The overall evaluation of the results shows that argon is highly effective and can be recommended as a refining medium.

\section{ACKNOWLEDGEMENTS}

\section{This article was made possible by the financial support of the "Student Grant Competition" projects SP2021/39 and SP2021/41 and by the project of MEYS CZ.02.1.01/0.0/0.0/17_049/0008399}

\section{REFERENCES}

[1] MITRASINOVIC, A., ROBLESHERNÁNDEZ, F. C., DJURDJEVIC, M., SOKOLOWSKI, J. H. On-line prediction of the melt hydrogen and casting porosity level in 319 aluminum alloy using thermal analysis. Materials Science and Engineering: $A$. [online]. 2006, vol. 428, no. 1-2, pp. 41-46. Available from: https://doi.org/10.1016/j.msea.2006.04.084

[2] ZHAO, L., PAN, Y., LIAO, H., WANG, Q. Degassing of aluminum alloys during remelting. Materials Letters. [online]. 2012, vol. 66, iss. 1, pp. 328-331. Available from: https://doi.org/10.1016/j.matlet.2011.09.012.

[3] KIM, M. J., YUN J. P., YANG J. B. R., CHOI S. J., KIM D. Prediction of the temperature of liquid aluminum and the dissolved hydrogen content in liquid aluminum with a machine learning approach. Metals. [online]. 2020, vol. 10, no. 3, p. 330. Available from: https://doi.org/10.3390/met10030330.

[4] LIU, Y., JIE, W., GAO, Z., ZHENG, Y. Investigation on the formation of microporosity in aluminum alloys. Journal of Alloys and Compounds. [online]. 2015, vol. 629, pp. 221-229. Available from: https://doi.org/10.1016/i.jallcom.2015.01.009

[5] HAGHAYEGHIA, R., BAHAI, H., KAPRANOSC, P. Effect of ultrasonic argon degassing on dissolved hydrogen in aluminum alloy. Materials Letters. [online]. 2012, vol. 82, pp. 230-232. Available from: https://doi.org/10.1016/j.matlet.2012.05.112.

[6] HERNÁNDEZ-HERNÁNDEZ, M., CAMACHO-MARTÍNEZ, J. L., GONZÁLEZ-RIVERA, C., RAMÍREZ-ARGÁEZ, M. A. Impeller design assisted by physical modeling and pilot plant trials. Journal of Materials Processing Technology. [online]. 2016, vol. 236, pp. 1-8. Available from: https://doi.org/10.1016/j.jmatprotec.2016.04.031.

[7] MOSTAFAEI, M., GHOBADI, M., EISAABADI, B. G., ULUDAĞ, M., TIRYAKIOĞLU, M. Evaluationofthe effects of rotary degassing process variables on the quality of $A 357$ aluminum alloy castings. Metall. Mater. Trans. $B$. [online]. 2016, vol. 47, pp. 3469-3475. Available from: https://doi.org/10.1007/s11663-016-0786-7.

[8] GYARMATI, G., FEGYVERNEKI, G., TOKÁR, M., MENDE, T. The effects of rotary degassing treatments on the melt quality of an Al-Si casting alloy. International Journal of Metalcasting. [online]. 2021, vol. 15, iss. 1, pp. 141151. Available from: https://doi.org/10.1007/s40962-020-00428-z.

[9] WARKE, V. S., SHANKAR, S., MAKHLOUF, M. M. Mathematical modeling and computer simulation of molten aluminum cleaning by the rotating impeller degasser: Part II. Removal of hydrogen gas and solid particles. Journal of Materials Processing Technology. [online]. 2005, vol. 168, iss. 1, pp. 119-126. Available from: https://doi.org/10.1016/j.jmatprotec.2004.10.016

[10] WU, R., SHU, D., SUN, B., WANG, J., LI, F., CHEN, H., LU, Y. Theoretical analysis and experimental study of spray degassing method. Materials Science and Engineering: A. [online]. 2005, vol. 408, iss. 1-2, pp. 19-25. Available from: https://doi.org/10.1016/j.msea.2005.05.055

[11] PUGA, H., BARBOSA, J., SEABRA, E., RIBEIRO, S., PROKIC, M. New trends in aluminum degassing a comparative study. In: Fourth International Conference on Advances and Trends in Engineering Materials and their Applications (AES - ATEMA' 2009). [online]. Hamburg: AES, 2009, pp. 1-5. 
[12] LICHÝ, P., BAJEROVÁ, M., KROUPOVÁ, I., OBZINA, T. Refining aluminum-alloy melts with graphite rotors. Materiali in Tehnologije. [online]. 2020, vol. 54, no. 2, pp. 263-265. ISSN 1580-3414. Available from: https://doi.org/10.17222/mit.2019.147.

[13] RAISZADEH, R., GRIFFITHS, W. D. A method to study the history of a double oxide film defect in liquid aluminum alloys. Metallurgical and Materials Transactions B. [online]. 2006, vol. 37 B, pp. 865-871.

[14] TREMBLAY, É., MALTAIS, B. The use of nitrogen to degas molten aluminum. Comparison of metallurgical results with argon and nitrogen used in an ACD ${ }^{\mathrm{tm}}$. In: Light Metals: The Minerals, Metals \& Materials Series. [online]. Ratvik A: 2017. Springer, Cham, 2017, pp. 1475-1480. Available from: https://doi.org/10.1007/978-3-319-51541$0 \quad 176$. 